\title{
Electromagnetic Fields and Human Beings: A Person-Centered Approach to Human Technology
}

\author{
Bahram Ghandchi ${ }^{1}$, Trevor Archer ${ }^{2,3}$ and Danilo Garcia ${ }^{1-5^{*}}$ \\ ${ }^{1}$ Blekinge Centre of Competence, Blekinge County Council, Karlskrona, Sweden \\ ${ }^{2}$ Department of Psychology, University of Gothenburg, Gothenburg, Sweden \\ ${ }^{3}$ Network for Empowerment and Well-Being, Sweden \\ ${ }^{4}$ Institute of Neuroscience and Physiology, University of Gothenburg, Gothenburg, Sweden \\ ${ }^{5}$ Department of Psychology, Lund University, Lund, Sweden
}

\begin{abstract}
In this paper, we first briefly review the work from the World Health Organization (WHO; 1996), which recognized the need for research addressing the EMFs' influence on human health. The WHO has given guidelines focused mainly on three directives: Challenges, Competencies, and Context. In addition, we also briefly review the projects conducted by the European Union (EU) that have investigated the influence of EMFs on human beings. As the third part of this article, we briefly explain the work of a unit of the International Telecom Union (ITU), the Telecommunication Standardization Sector (ITU-T), which assembles experts from around the world to develop international standards for communication systems. At the end of this article we make some suggestions for further research based on the nature of human beings, person-centered research, and the Science of Well-being.
\end{abstract}

Keywords: Electromagnetic fields; European Union; International Telecom Union; Person-centered methods; Science of well-being; World Health Organization

\section{Introduction}

In our daily life we are exposed to Electromagnetic fields (EMFs) from different sources, natural and man-made. Some of them are visible; such as the sunlight, and other are invisible; such as, infrared and ultraviolent waves. Another example from nature is electric fields during thunderstorms that cause lightning to leap across the sky. EMFs are indeed well known to us; the Earth's magnetic field causes compasses' needles to point North and helps birds and fishes to navigate. Electric and magnetic fields are linked because whenever an electric current flows in an electric field, then a magnetic field is generated and together they form an EMF [1]. An example of manmade EMFs can be found in hi-fi systems in our homes, where an electric field, or voltage, drives a varying electric current that produces a varying magnetic field that causes the speaker cone to vibrate and reproduce sounds. EMFs also arise from microwave ovens, hairdryers, the electric wiring in houses, and remote control devices, computer screens, and electric motors, among others. Additionally, humans are also exposed to EMFs from electric train and tram cables, power lines, radio-frequency communication antennas for emergency services, and now, with the growth of wireless networks, from Wi-Fi and 'Bluetooth' type technologies. One of the main sources of EMFs are mobile phones and wireless networks, which usage have grown rapidly during the last decades. Mobile phones generate EMFs in two ways, one from the antenna mast that covers the specific area in which a person with a mobile phone is and the other from the phone to the antenna mast when we are in a mobile phone call [1]. Importantly, although there are many sources, these EMFs are most of the time relatively weak.

In this paper, we first briefly review the work from the World Health Organization (WHO; 1996), which recognized the need for research addressing the EMFs' influence on human health. The WHO has given guidelines focused mainly on three directives: Challenges, Competencies, and Context. In addition, we also briefly review the projects conducted by the European Union (EU) that have investigated the influence of EMFs on human beings. As the third part of this article, we briefly explain the work of a unit of the International Telecom Union (ITU), the Telecommunication Standardization Sector (ITU-T), which assembles experts from around the world to develop international standards for communication systems. At the end of this article we make some suggestions for further research based on the nature of human beings, person-centered research, and the Science of WellBeing $[2,3]$.

\section{The World Health Organization (WHO): Guideline}

The WHO is the directing and coordinating authority for health within the United Nations and has the responsibility for:

1. Providing leadership on global health matters,

2. Shaping the health research agenda,

3. Setting norms and standards,

4. Articulating evidence based policy options,

5. Providing technical support to countries, and

6. Monitoring and assessing health trends.

In 1996 the WHO recognized EMFs as a rapid growing factor on public anxiety, so the WHO focused on Challenges, Competencies, and Context in order to create guidelines on EMFs and the health of the human population. The WHO mapped EMFs' risk issues for each country and for regions, like EU, and globally as well (i.e., Challenges).

*Corresponding author: Garcia D, Network for Empowerment and Well-Being, Axel W. Anderssons Väg 8A, SE 371 62, Lyckeby, Sweden, Tel: +46 317864694 ; E-mail: danilo.garcia@icloud.com

Received: August 14, 2016; Accepted: August 29, 2016; Published: September 05, 2016

Citation: Ghandchi B, Archer T, Garcia D (2016) Electromagnetic Fields and Human Beings: A Person-Centered Approach to Human Technology. Clin Exp Psychol 2: 138. doi: 10.4172/2471-2701.1000138

Copyright: (c) 2016 Ghandchi B, et al. This is an open-access article distributed under the terms of the Creative Commons Attribution License, which permits unrestricted use, distribution, and reproduction in any medium, provided the original author and source are credited. 
With regard to Competencies, the WHO suggested that scientific expertise, communication skills, and corporate, and regulatory judgment should be used to mitigate EMFs' risks and challenges through risk management, risk perception, and risk assessment. So at the end, the WHO came up with one guideline to establish a dialogue on risks from EMFs, to research, identify, analyze, and mitigate the effects of EMFs on health (WHO, 2002). The WHO has assessed the scientific evidence of possible health effects of EMFs in the frequency range from 0 to $300 \mathrm{GHz}$. Extensive research has been conducted into the potential health hazards of exposure to many parts of the frequency spectrum, including the radio frequency EMFs (RF-EMF) used by mobile phones, base stations and other wireless systems and services. Expert review groups mandated by national or international authorities have analyzed the data emerging from this research in more than 150 reports. Weighing the whole body of evidence, there is no evidence to convince experts that exposure below the guidelines set by the International Commission on Non-Ionizing Radiation Protection carries any health risks, for adults, pregnant women or children. Further information about the WHO's EMFs Project can be found at: http://www.who.int/emf.

\section{The European Union (EU): Research}

The EU acknowledges that technologies that use and generate EMFs bring lots of benefits to our life and also the fact that nowadays we seem not to be able to live and do anything without them. However, the EU also acknowledges that we need to understand and have health standards to avoid any consequence of EMFs (EU EMF Report 2005). EU funded eight major projects aiming to increasing our understanding about the influence of EMFs on human beings under the Framework Programs between 1998 and 2002. This funding continued between 2002 and 2006. The majority of these research projects focused on EMFs from mobile phones and their relationship to the development of cancer. A smaller number of projects investigated possible effects on hearing, memory, and behavior. Researchers conducted the studies in two different ways: (1) in vitro research was based on laboratory experiments using biological materials, for example, cell cultures; and (2) in vivo research was performed on living organisms, such as rats or humans. A summary of some of projects is listed in Table 1. All in all, The EU stated that there is no evidence that mobile technology used between 1998-2002 influences health in a harmful way. Nevertheless, one of the rapports was confidential (i.e., The Perform-A). In addition, the $\mathrm{EU}$ recommended that more research is needed on the next generation of mobile technology (i.e., The Guard Project).

\section{International Telecom Union (ITU): Standards}

The ITU's unit Telecommunication Standardization Sector (ITU-T) assembled experts from around the world to develop international standards that act as defining elements in the global infrastructure of information and communication technologies (ICTs). Standards are critical to the interoperability of ICTs when users exchange voice, video or data messages in another country, because standards enable global communications by ensuring that countries' ICT networks and devices are speaking the same language.

Within ITU's organization there are lots of units with different visions and assignments. The 5's units' (SG5) mission is to do research on methodologies for evaluation of ICT's effects on climate change and publishing guidelines for using ICTs in an eco-friendly way. In recent years one of the SG5's focuses has been studies about technical frameworks for responsible management of the ICT systems that underpin wireless communications. The aim of these studies is to give operators, manufacturers and government agencies the tools required to assess EMFs' levels and to verify compliance with the recommended human-exposure guidelines set out by the WHO, the International Commission on Non-Ionizing Radiation Protection, and the IEEE International Committee Electromagnetic Safety (ICES). The SG5 activities are mentioned in more detail below.

\section{EMF report}

A new report from Latin America measuring EMFs provides an overview on how compliance with national and international standards can assist the management and mitigation of public concerns pertaining to EMFs, making it easier to garner social acceptance for the installation of new wireless technologies. It also presents case studies

\begin{tabular}{|c|c|c|c|}
\hline Projects Name & Purpose & Methodology & Results and Conclusions \\
\hline $\begin{array}{l}\text { The Cemfec } \\
\text { Project }\end{array}$ & $\begin{array}{l}\text { To Investigate whether EMFs transmission from } \\
\text { Mobile Phone could act as a co-carcinogen. }\end{array}$ & in vitro - in vivo & $\begin{array}{c}\text { Typical RF-EMF exposure of mobile phones did not enhance the cancer- } \\
\text { causing activity of the MX chemical carcinogen widely present in our drinking } \\
\text { water, animals or cell cultures. }\end{array}$ \\
\hline $\begin{array}{l}\text { The Guard } \\
\text { Project }\end{array}$ & $\begin{array}{l}\text { To investigate the potential effects of digital mobile } \\
\text { phones on hearing. }\end{array}$ & in vitro - in vivo & $\begin{array}{l}\text { No adverse effects on the hearing of the animals }(N=490) \text { or humans }(N \\
=550) \text {. Researchers suggested the need of investigating the effects of } 3 G \\
\text { systems, which have not yet been studied. }\end{array}$ \\
\hline $\begin{array}{l}\text { The } \\
\text { Interphone } \\
\text { Project }\end{array}$ & $\begin{array}{l}\text { To extend our limited knowledge of possible link } \\
\text { between cancer and RF-EMF. }\end{array}$ & in vitro - in vivo & $\begin{array}{l}\text { The project published analysis of data on acustic neuromas from five Nordic } \\
\text { countries. For example, data from Denmark suggested no increase linked to } \\
\text { use mobile phones, data from Sweden suggested an increase, but below the } \\
\text { risk area, and the rest showed no risk. }\end{array}$ \\
\hline $\begin{array}{c}\text { The Perform-A } \\
\text { Project }\end{array}$ & $\begin{array}{l}\text { To clarify whether RF-EMFs cause or increases } \\
\text { cancer in animals.t }\end{array}$ & in vivo & $\begin{array}{l}\text { The results and conclusions are confidential between the EU, WHO, and the } \\
\text { sponsors. }\end{array}$ \\
\hline $\begin{array}{l}\text { The Ramp } \\
2001 \text { Project }\end{array}$ & $\begin{array}{l}\text { Does current safety limits of RF-EMF can anyhow } \\
\text { cause cellular or molecular changes in the brain. }\end{array}$ & in vitro - in vivo & There was no particular effect of RF-EMF exposure. \\
\hline $\begin{array}{l}\text { The Reflex } \\
\text { Project }\end{array}$ & $\begin{array}{l}\text { To investigate whether ELF-EMF and RF.EMF } \\
\text { influence human health. }\end{array}$ & in vitro & $\begin{array}{l}\text { ELF-EMFs and RF-EMFs caused, in human and animal cells cultured in the } \\
\text { laboratory, several genotoxic effects as well as effects on gene expression } \\
\text { However, before any conclusions can be drawn regarding the risks to human } \\
\text { health, the results will have to be complemented by whole animal studies. }\end{array}$ \\
\hline $\begin{array}{c}\text { The THz } \\
\text { Bridge Project }\end{array}$ & $\begin{array}{c}\text { In this project TeraHertz (THz) radiation was used } \\
\text { to study the potential damage of EMF's radiation on } \\
\text { biological systems. }\end{array}$ & in vitro - in vivo & $\begin{array}{l}\text { No biological effects, but in some cases they discovered a change in the ability } \\
\text { of certain chemical compounds to flow through artificially created membranes. }\end{array}$ \\
\hline $\begin{array}{l}\text { The Advice } \\
\text { Pulsed Fields } \\
\text { Project }\end{array}$ & $\begin{array}{l}\text { To investigate the effects of security systems that } \\
\text { operate by generating pulsed EMFs. }\end{array}$ & in vitro - in vivo & $\begin{array}{l}\text { No signs on that exposure guidelines were exceeded. Two recommendations: } \\
\text { (1) to increasing efforts for the measurement of exposure levels and (2) that } \\
\text { technical information should be provided to customers.. }\end{array}$ \\
\hline
\end{tabular}

Table 1: Summary of selected projects funded by the EU during the years 1998 to 2002. 
on the continuous monitoring systems installed in some countries in Latin America, as well as the policies adopted at governmental level for the implementation of Recommendation ITU-T K.83 in Latin America.

\section{The EMFs application}

The EMFs Application, designed for smart phones, tablets, or desktops, provides information and education resources on EMFs suitability for all communities, stakeholders and governments and is available online in six different languages (http://emfguide.itu.int or at iOS, Blackberry World and Google Play app store). The mobile application does real site measurements and modeling of the multiple sources operating on different frequencies and transmitting antennas. The application determines the validity of EMFs that are being measured; process and guides using numerical modeling of EMFs in the areas around telecommunication transmitting antennas and other various systems. The application works on existing Specific Absorption Rate measuring and calculating procedures, techniques and protocols for evaluating EMFs.

\section{EMFs considerations in smart sustainable cities}

Wireless and wired networks provide the underlying connections that underpin smart sustainable cities. According to the SG5, the design and deployment of wireless networks should aim to ensure compliance with the required quality of service as well as with the standards and regulations on human exposure to RF-EMFs. The technical report details the considerations that need to be taken with respect to EMFs in smart sustainable cities to ensure that the networks and connected devices operate safely and efficiently. Efficient deployment of wireless infrastructure will reduce the transmitted radio frequency power in providing services and improve the efficiency of ICTs. The key audience of this technical report includes city officials, town planners, urban developers, infrastructure providers, network operators and the public. The three sub-activities are briefly described next:

The first activity called ICTs and EMFs provides information about how ICTs get support from wireless network in the community and service providing that includes smart metering, remote healthcare, medical monitoring, smart home, and education. The second activity called EMFs and Health gives huge and deep knowledge about EMFs health effect based on WHO directives. Another sub-activity is EMF exposure limits that provides and collect valuable information from various resources regarding EMF exposure limits from the International Commission on Non-Ionizing Radiation Protection with more information about limitation for workers and information about general public safety to give more awareness about linkage between EMFs exposure, health, and safety. In addition, also informing communities to increase public and policymaker awareness and help citizens to get engaged better into this issue. On the other hand ITU provides different technical information regarding ICT network infrastructure and different wireless technologies like WiMAX, 3G, 4G. The ICT also helps to increase awareness about how different technology usage have an effect on the environment and the approval process for planning on good policy making of ICT networks. This information is available for all countries and communities to decrease the level of EMFs exposure in their society.

\section{Summary}

We have briefly reviewed the work done by the WHO, EU, and ITU. We consider that in order to understand the influence and effect of EMFs on human health, these organizations have given guidance (e.g., WHO's Challenge, Competence, and Context), knowledge (e.g., EU's
EMFs research), and technical standards and advice (e et al., .g., ITU's technical reports) (see Figure 1). At this point, the reports about EMFs' influence on health suggest that as long as the short range frequencies of VHF (between $62 \mathrm{MHz}$ to $90 \mathrm{MHz}$ ) are used, there should be no health impairments. At the present, however, in order to keep the quality of mobile services (e.g., voice, text, and high speed data), the public is exposed to higher frequency ranges (e.g., $900 \mathrm{MHz}, 1800 \mathrm{MHz}$, and $2100 \mathrm{MHz}$ ) on a daily basis. Although, to the best of our knowledge, no study shows that such high ranges are bad for human health, no studies seem to entirely dismiss it. One possible explanation could be that high-frequency voltage transients, which are superimposed on 50/60$\mathrm{Hz}$ fields but are generally not measured, are the real causal agent. This is, however, not based on scientific data of acceptable standard for such claims [4]. Additionally, individuals presenting idiopathic environmental intolerance attributed to EMFs display a higher than random detection performance ( $\mathrm{d}$ index of signal detection theory) whereas no difference in their bias ( $\beta$ index) toward the presence of the magnetic field was observed [5]. Hence, people with high sensitivity to EMFs might be able to detect the presence of the EMFs to a small extent; however, their symptom reports are connected to perceived exposure. That being said, we certainly agree that to scrutinize the effects if EMFs on human health should indeed be an imperative for the coming years.

\section{Conclusion and Recommendations}

In recent years, public health care has been addressed using personcentered approaches [6,7]. The use of a person-centered approach in health care, in contrast to a patient-centered one, focuses in individual interrelationships over time, views diseases as interrelated phenomena, views body systems as interrelated, allows for the person's own health concerns in their own treatment, and follows the development of people's health problems as well as the diseases (see [8] for a clear differentiation between patient-centered and person-centered care). In this context, high risk perception of EMFs waves associated with cellular phones usage was observed when the affected subjects contemplated that they had more personal knowledge [9]. Furthermore, negative inductions produced by EMFs may be the source of hippocampus dysregulation, thus affecting the regulation of emotions, everyday behavior, motivation, and cognitive functions [10]. In this line of thought we propose a person-center approach to innovate human technology that might or might not be endangering our health [11]. For instance, the human body works at $62-68 \mathrm{MHz}$ and the human brain works at $72-90$
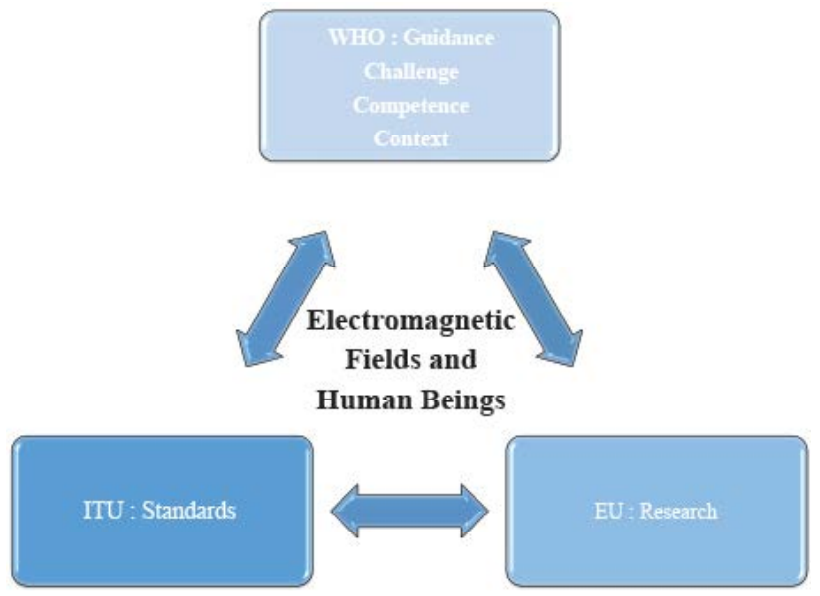

Figure 1: The contribution on the influence and effect of electromagnetic fields (EMFs) on human health by the World Health Organization (WHO), the European Union (EU), and the International Telecom Union (ITU). 
Citation: Ghandchi B, Archer T, Garcia D (2016) Electromagnetic Fields and Human Beings: A Person-Centered Approach to Human Technology. Clin Exp Psychol 2: 138. doi: 10.4172/2471-2701.1000138

Page 4 of 4

$\mathrm{MHz}$ like open circuits, thus, exposure could be balanced or limited to this range [12].

On this basis, we suggest a quest for the development of new technical paradigms that take into account the human being and nature as the model. At this moment, critics will say that it is impossible to keep the same quality of services with short-range frequency waves. We agree on that it will be difficult, but not impossible, especially as long as we have nature as our guide.

"I follow Nature, the best of guides, as I would a god, and am loyal to her commands."

\section{Cicero.}

\section{Competing Interests}

Dr. Dr. Danilo Garcia is the Director of the Blekinge Center of Competence, which is the Blekinge County Council's research and development unit. Bahram Ghandchi is a research project manager at the Blekinge Center of Competence. The Center works on innovations in public health and practice through interdisciplinary scientific research, person-centered methods, community projects, and the dissemination of knowledge in order to increase the quality of life of the habitants of the county of Blekinge, Sweden. Dr. Danilo Garcia is also an Associate Professor at the University of Gothenburg and together with Professor Trevor Archer and Associate Professor Max Rapp Ricciardi, the leading researcher of the Network for Empowerment and Well-Being

\section{Author Contributions}

Bahram Ghandchi and Danilo Garcia conceived and designed and wrote the paper, prepared figures and/or tables, reviewed drafts of the paper. Trevor Archer reviewed drafts of the paper.

\section{References}

1. Patermann C (2005) Health and electromagnetic fields.

2. Cloninger CR (2003) A psychobiological model of temperament and character: TCl. Yeni Symposium 41: 86-97.

3. Cloninger CR (2004) Feeling good: The science of well-being. The British Journal of Psychiatry.

4. de Vocht F, Olsen RG (2016) Systematic Review of the Exposure Assessment and Epidemiology of High-Frequency Voltage Transients. Frontiers in Public Health 4: 52.

5. Szemerszky R, Gubányi M, Árvai D, Dömötör Z, Köteles F (2015) Is There a Connection Between Electrosensitivity and Electrosensibility? A Replication Study. International Journal of Behavioral Medicine 22: 755-763.

6. Wong KM, Cloninger CR (2010) A person-centered approach to clinical practice. Focus 8: 199-215.

7. Ekman I, Swedberg K, Taft C, Lindseth A, Norberg A, et al. (2011) PersonCentered Care - Ready for Prime Time. Eur J Cardiovasc Nurs 10: 248-251.

8. Starfield B (2011) Is patient-centered care the same as person-focused care? The Permanente Journal 15: 63-69.

9. Kim K, Kim HJ, Song DJ, Cho YM, Choi JW (2014) Risk perception and public concerns of electromagnetic waves from cellular phones in Korea. Bioelectromagnetics 35: 235-244.

10. Teimori F, Khaki AA, Rajabzadeh A, Roshangar $L$ (2016) The effects of 30 $\mathrm{mT}$ electromagnetic fields on hippocampus cells of rats. Surg Neurol Int 7: 70 .

11. Grellier J, Ravazzani P, Cardis E (2014) Potential health impacts of residential exposures to extremely low frequency magnetic fields in Europe. Environ Int 62: $55-63$

12. Higley C, Higley A (2012) The Reference Guide to Essential Oils. Pubilsher: Place. 